\title{
Effect of Placental Cord Drainage on the Third Stage of Labour Progress and Incidence of Postpartum Hemorrhage: Randomized Controlled Clinical Trial
}

\author{
Wafaa Taha Ibrahim Elgzar ${ }^{1 *}$, Hanan Ibrahim Ibrahim ${ }^{1}$, Hanan Heiba Elkhateeb ${ }^{2}$ \\ ${ }^{1}$ Obstetrics and Gynaecology Nursing, Damanhour University, Damanhour, Egypt \\ ${ }^{2}$ Obstetrics and Gynaecology Medicine, General Organization of Teaching Hospitals and Institutes, Damanhour, Egypt \\ *Corresponding Author \\ Wafaa Taha Ibrahim Elgzar (wafaa.elgzar@nur.dmu.edu.eg)
}

\section{Article History}

Received: 30.12.2019

Accepted: 07.01.2020

Published: 19.01.2020

\begin{abstract}
Background: Postpartum hemorrhage (PPH) is accountable for around $25 \%$ of maternal mortality in the developing countries. Management of $3^{\text {rd }}$ stage of labour is the cornerstone in PPH prevention. The effect of Placenta Cord Drainage (PCD) on the $3^{\text {rd }}$ progress and PPH prevention is still controversy. Aim of the study: This study aims to investigate the effect of placental drainage on the third stage of labour progress and incidence of postpartum hemorrhage. Research design: randomized controlled clinical trial. Setting: This study is conducted at normal labour unit at Damanhour educational institution affiliated to ministry of health at Elbehira governorate/Egypt. Sampling: A purposive sample of 120 women undergoing normal easy vaginal delivery. Tools: two tools were used for data collection. Tool I: sociodemographic characteristics and obstetric history interview schedule. Tool II: Labour assessment sheet it consists of three main parts. Part I: Summary of the first and second stage of labor. Part II: third stage assessment sheet. Part III: 3. Early postpartum assessment sheet. Results: The present study results shows no statistical significant differences between PCD and control group regarding vital signs during the 3rd stage, uterus condition after placenta delivery, type, dose and route of uterotonic drugs given during 3rd stage. On the contrary, a statistical significant reduction in the time elapsed until appearance of placenta separation signs $(3.5583 \pm 0.83915)$, 3rd stage duration $(5.1417 \pm 1.03138)$, amount of blood loss during 3rd stage (195.45 \pm 13.994$)$, placenta weight $(580.333 \pm 64.97631)$ and incidence of retained placenta $((0 \%)$ in the PCD group than control. In the early postpartum assessment, the mean pulse $(88.2 .7667 \pm 3.11022)$ is higher among control group compared to PCD $(83.4667 \pm 2.78292)$ group. Control group needs higher dose of uterotonic $(8.6780 \pm 2.62902)$ drugs than PCD $(5.0566 \pm 1.41985)$ group. In addition, maternal hemoglobin $(9.5234 \pm 0.6087)$ is slightly higher in PCD group compared to control (8.458 \pm 0.873$)$. Conclusion: PCD is safe, effective noninvasive intervention that may help in improving $3^{\text {rd }}$ stage progress. Recommendation: PCD should be added to third stage of labour intervention protocol.
\end{abstract}

Keywords: Placenta Cord Drainage, Third Stage of Labour, Postpartum Hemorrhage.

\section{INTRODUCTION}

Although, pregnancy is normal physiological event, it is still threaten women life. Every morning 830 woman die worldwide due to pregnancy and labour complications leaving 830 family without mother. Nearly, all (99\%) of them occurs in the developing world [1]. In Egypt, 1400 mothers and 50\% of their neonates die every year from pregnancy and child birth complications. Maternal mortality rate (MMR) is still high in Egypt compared to worldwide norms. Therefore, further attempts should be created to implement major health strategies for its reduction [2]. The availability of standardized emergency obstetric care is considered the first most important strategy to decrease maternal mortality [3]. Furthermore, One of the targets under Sustainable Development Goal III is to decrease worldwide MMR to lower than 70 per 100000 births between 2016 and 2030. Hemorrhage (especially intra and post-partum), sepsis and eclampsia are the chief causes of maternal deaths. Furthermore, the preexisting diseases that are triggered by pregnancy play indirect role in increasing maternal mortality [4].

Copyright @ 2020: This is an open-access article distributed under the terms of the Creative Commons Attribution license which permits unrestricted use, distribution, and reproduction in any medium for non commercial use (NonCommercial, or CC-BY-NC) provided the original author and source are credited. 
Postpartum hemorrhage (PPH) is a critical obstetric emergency, particularly in the presence of pre-existing maternal anemia and/or antepartum hemorrhage. Internationally, it is the central cause of around $25 \%$ of all maternal mortality. PPH is the first direct leading cause of maternal deaths in developing countries. It is accountable for one-third of all pregnancy-related mortalities in Africa, Asia, and roughly 140,000 mortalities per year in Egypt [5-7]. The $3^{\text {rd }}$ stage prolongation is considered the first cause of PPH. Preventive measures to reduce $3{ }^{\text {rd }}$ stage complications are suggested for all women undergoing childbirth [8].

The $3^{\text {rd }}$ stage of labour started after fetus complete expulsion and ends by placenta complete expulsion. The $3^{\text {rd }}$ stage prolongation leads to enhanced probability of sever maternal complications and death as well. Theses complications include uterine atony, retained placenta, postpartum hemorrhage (PPH), hemorrhagic shock, and even maternal death [9, 10]. Uterine atony is the chief cause of PPH [11]. Timely placenta expulsion and an effective uterine contraction to stop bleeding are key element to prevent $3^{\text {rd }}$ stage complications [12].

Placental expulsion depends its separation from uterine wall, capillary hemorrhage, contractility of the uterine muscle, maternal effort, and gravity effect on the placenta [12]. Placenta delivery is generally completed within 15 minutes following the fetus delivery in $90 \%$ of parturient $[10,13]$. Two distinct methods are usually used to manage the $3^{\text {rd }}$ stage of labor. They are active and physiological/expectant management. The active management includes oxytocic administration, umbilical cord early clamping and cutting, and the controlled cord traction [7, 11]. The physiological or expectant management primarily includes maternal effort supported by gravity, nipple stimulation through breast feeding and skin-to-skin contact rapidly after birth, nipple stimulation increasing maternal oxytocin concentrations and strengthening the uterine contractions that will assist the placental separation and control bleeding [14, 15]. In females at low PPH risk, several researches have reported that active pharmacological management does not decrease blood loss when compared with physiological expectant management [16].

Nowadays, it is prevalent practice in the active $3^{\text {rd }}$ stage management to clamp umbilical cord at both maternal and fetus sides and then cut it. After appearance of placenta separation signs it is delivered through controlled cord traction (Andrews brand maneuver) [17]. The new trend in $3^{\text {rd }}$ stage management is placenta cord drainage (PCD). The hypothesis behind this technique is that low weight of the placenta may facilitate its delivery. From the physiological point of view, PCD may decrease its bulkiness, consequently, it increase the uterine contractility and make it more efficient. Effective uterine contraction mostly will shorten the $3^{\text {rd }}$ stage duration and decrease the risk for PPH [17]. PCD includes clamping the umbilical cord immediately after fetus delivery from maternal and fetus side until cutting the cord and then unclamping the maternal side to allow placental blood drainage. Complete flow of the placental blood should be maintained into suitable container $[18,19]$.

Although the researches about PCD have long history, no clear conclusion had been drown on its beneficial or harmful effects. In 1999, Razmkhah [18] first noted that, when using the PCD technique, the length of $3^{\text {rd }}$ stage of labor was considerably shorter. Equivalent findings were revealed by other investigators [16, 20]. A Cochrane review also reported a decrease in the $3^{\text {rd }}$ stage duration with PCD [19]. However, other one study [21] discovered no additional advantage from PCD. As regard postpartum complications, most trials discovered no important rise in post-partum complication with PCD [16, 18, 20]. However, PPH was increased in one study [21]. In addition, in clinical practice, PCD is still not commonly used. These contradictory results necessitate several studies to fill the knowledge and practice gap in this respect.

\section{Methodology}

\section{Aim of the Study}

This study aims to investigate the effect of Placental Cord Drainage (PCD) on the third stage of labour progress and incidence of postpartum hemorrhage.

\section{Operational Definition}

$3^{\text {rd }}$ stage labour progress in this study refers to the $3^{\text {rd }}$ stage duration, time elapsed until appearance of placental separation signs, amount of blood loss during the 3rd stage of labour, incidence of retained placenta, and need for blood transfusion during the early postpartum period.

\section{Research Hypothesis}

H0: Women who are exposed to PCD have the same $3^{\text {rd }}$ stage progress and incidence of PPH as control group. H1: Women who are exposed to PCD have more favorable $3^{\text {rd }}$ stage progress and lower incidence of PPH than control group. 
Research Design: Randomized controlled clinical trial.

Setting: This study is conducted at normal labour unit at Damanhour educational institution affiliated to ministry of health at Elbehira governorate/Egypt.

\section{Sampling}

A purposive sample composed of 120 women undergoing normal easy vaginal delivery. Inclusion criteria are normal pregnancy, aged 20 to 35 years, full term singleton pregnancy, normal first and second stage of labour and agree to participate in the study. Women who exposed to any pregnancy or labour (first and second stage) complications were excluded from the study.

\section{Sample Size}

Sample size was calculated using Epi-info program using the following data: target population 920 in the last 6 months, acceptable error 5\%, expected frequency 50\%, confidence coefficient 95\%. Sample size =120 women.

\section{Sampling Technique}

The selected participants were assigned randomly to either PCD or control group using randomization block technique. This technique was done manually according the subsequent flowing steps: A list was prepared on the computer that contained numbers from 1 to 120 . Two copies were printed from this list.

One of the two lists was cut to small pieces. Each piece contained one number from 1 to 120 . The papers pieces are rolled up until all numbers become investable then they were put in large ball. The 120 pieces of papers were randomly allocated to six blocks, each one contain 20 random pieces of paper. From each block, 10 pieces of papers were randomly picked to be cases and the remaining 10 are considered control. Finally, the researchers register in front of each number, in the previously prepared list, it will be case or control. This list was used as a guide during data collection process. A total of 60 participants were considered potential cases and 60 participants were considered potential control. The list is saved in closed envelop that is opened immediately at time of data collection.

\section{Tools of Data Collection}

\section{Tool I: sociodemographic characteristics and obstetric history interview schedule.}

The researchers developed it after reviewing the current literatures to collect basic data. It composed of two main parts. Part I: include sociodemographic characteristics as age residence, occupation and level of education. Part II: Obstetrical history, it include gravidity, parity, gestational age, pre-delivery Hb, pre-delivery HCT, history of postpartum hemorrhage, retained placenta, and previous labour complications. It also includes weight and height.

\section{Tool II: Lbour assessment sheet}

It consists of three main parts. Part I: Summary of the first and second stage of labor. It collect data like duration of the $1^{\text {st }}$ stage of labor, duration of the $2^{\text {nd }}$ stage of labor, newborn birth weight and incidence of episiotomy or tears. Part II: third stage assessment sheet. It composed of eleven open and close-ended questions those asses the labour progress during $3^{\text {rd }}$ stage of labour and intervention done. Part III:. Early postpartum assessment sheet. It encompass eight questions to assess the maternal condition during the first 24 hours postpartum and incidence of PPH. It also describe the intervention done in the first 24 as blood transfusion.

\section{FILED WORK}

1. The study purpose had been clarified to the responsible authority in the college of nursing to obtain their agreement. An official letter was taken from nursing college at Damanhour University and directed to Damanhour National Medical institute to gain their permission to carry out the research after explanation of its purpose and scientific background.

2. The researchers developed all tools after intensive reviewing of the relevant literatures.

3. Tools content validity has been tested by jury of five expertise in the filled of obstetrics and gynecology nursing and one of the statistics filed. Tools reliability has been tested using Cronbach alpha coefficient test $(\mathrm{r}=0.81)$.

4. Clinical work:

- Data were collected over a period of 6 months from the beginning of March until end of August 2019.

- The study had been conducted on women undergoing normal vaginal deliveries who fulfilled the inclusion criteria.

- Ethical consideration: Oral consent was taken from each woman in the study and control group after clarification of the study purpose. Each woman is interviewed in complete privacy and assured that all her data are confidential and will be used only for research purpose only. She was informed about her right to reject participation without any consequences. 
- Tool I was collected from the woman record at time of first stage of labour.

- $\quad 1^{\text {st }}$ and $2^{\text {nd }}$ stage of labour care were performed as routine for both PCD and control group. Early cord clamping and cutting is the routine procedure followed in both groups. All required data from the $1^{\text {st }}$ and $2^{\text {nd }}$ stage is collected by direct observation.

- Duration of $1^{\text {st }}, 2^{\text {nd }}$ and $3^{\text {rd }}$ stage of labour were calculated using stopwatch.

- Immediately at the time of fetus expulsion, the closed envelop is opened to know if the case is PCD or control group.

- Immediately after birth, the woman is injected with 5 IU of oxytocin intramuscular as routine after exclusion of its contraindications.

- For PCD group, few second after cord cutting its unclamped from the maternal side and put in container to receive drained blood. The cord is let to drain placental blood until it is stopped. The container used to collect blood is different from that was used to estimate the amount of blood loss during third stage of labour.

- For the control group: the cord remains clamped until the end of the third stage.

- For both group, placenta is delivered by controlled cord traction after appearance of placental separation signs. Once the uterus become hard, contracted and bleeding is stopped the remaining blood is removed from vagina. The doctor performed episiotomy repair and sterile sanitary pad was provided.

- Blood loss is collected in both groups using Kelly's pad, which is used from the beginning of the $3^{\text {rd }}$ stage. It is put under the woman buttocks and its tail is drained in clean metal bowel to collect blood loss. No cotton or gauze used at this time.

- The primary outcomes which was assessed in the two groups include: vital signs, time elapsed between fetus delivery and placenta separation signs, $3^{\text {rd }}$ stage duration, amount of blood loss during $3^{\text {rd }}$ stage, uterus condition after placenta separation, placenta weight, incidence of retained placenta.

- Secondary outcomes are assessed after the first 24 hours postpartum. The secondary outcomes include vital signs, PPH incidence, condition of the uterus, need of uterotonic drugs, type and dose of uterotonic drugs given, blood transfusion need.

\section{Data Analysis}

After completion of data collection it was feed to SPSS version 24. Data was explored using descriptive statistics such as number, percentage means \pm SD. Differences between the two group are examined using chi-square and fisher exact test.

\section{RESUlTS}

Table-1: Distribution of the study participants according to their sociodemographic characteristics and BMI

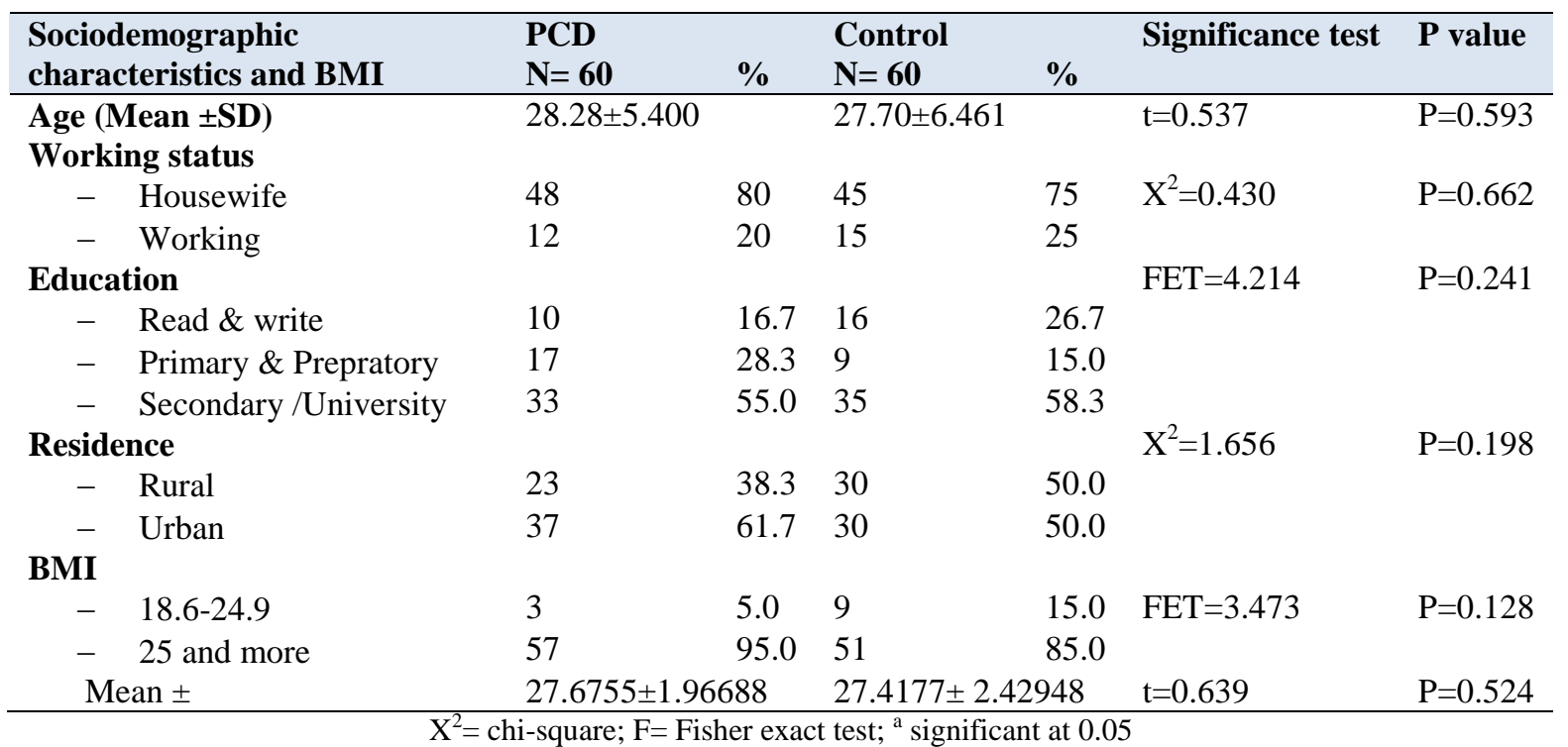

Table-1 shows no statistically significant differences between the PCD and control group regarding their sociodemographic characteristics. The mean age is 28.28 \pm 5.400 in PCD group compared to 27.70 \pm 6.461 in control. At the same time, $80 \%$ the PCD group are housewives compared to $75 \%$ of the control group. In addition, around half of both PCD (55\%) and control (58.3\%) group had secondary school or university education. Furthermore, $61.7 \%$ of the 
PCD group are urban area residence compared to $50 \%$ of the control group. The vast majority of PCD group (95\%) has BMI 25 and more compared to $85 \%$ among control group.

Table-2: Distribution of the study participants according to their obstetrical history and pre-delivery investigations

\begin{tabular}{|c|c|c|c|c|c|c|}
\hline Obstetrical history and predelivery investigations & \multicolumn{2}{|c|}{$\begin{array}{l}\text { PCD } \\
\text { Mean } \pm \text { SD }\end{array}$} & \multicolumn{2}{|c|}{$\begin{array}{l}\text { Control } \\
\text { Mean } \pm \text { SD }\end{array}$} & t test & $P$ value \\
\hline Gravidity: & $2.48 \pm 1$ & & $2.55 \pm$ & & 0.232 & 0.817 \\
\hline Parity & $1.467 \pm$ & 5781 & $1.517=$ & 7123 & 0.166 & 0.868 \\
\hline Gestational age & 39.187 & .8123 & 39.148 & 0.8123 & 0.248 & 0.805 \\
\hline Pre-delivery Hb & 11.103 & .8093 & $11.10^{3}$ & .7385 & 0.059 & 0.953 \\
\hline \multirow[t]{2}{*}{ Pre-delivery HCT } & 32.533 & .1821 & 31.950 & 2.1267 & 1.483 & 0.141 \\
\hline & $\mathbf{N}(\mathbf{6 0})$ & $\%$ & $\mathbf{N}(60)$ & $\%$ & & \\
\hline \multicolumn{7}{|l|}{ History of PPH } \\
\hline - Yes & 9 & 15.0 & 12 & 20.0 & $X^{2}=0.519$ & $\mathrm{P}=0.471$ \\
\hline$-\quad$ No & 51 & 85.0 & 48 & 80.0 & & \\
\hline \multicolumn{7}{|l|}{ History of retained placenta } \\
\hline- Yes & 5 & 8.3 & 10 & 16.7 & $X^{2}=1.905$ & $\mathrm{P}=0.269$ \\
\hline$-\quad$ No & 55 & 91.7 & 50 & 83.3 & & \\
\hline \multicolumn{7}{|l|}{ History of other labour complications } \\
\hline$-\quad$ Yes & 2 & 3.3 & 8 & 13.3 & $\mathrm{FET}=3.927$ & $\mathrm{P}=0.039^{\mathrm{a}}$ \\
\hline$-\quad$ No & 58 & 96.7 & 52 & 86.7 & & \\
\hline
\end{tabular}

Table-2 shows no statistically significant differences between both groups in relation to their obstetrics history and pre-delivery investigation except for history of other labour complications. The mean gravidity, parity, and gestational age is $2.48 \pm 1.490,1.467 \pm 1.5781$ and $39.187 \pm 0.8123$ among PCD compared to $2.55 \pm 1.651,1.517 \pm 1.7123$ and $39.148 \pm 0.8123$ among control group, respectively. Furthermore, the Pre-delivery Hb and HCT is $11.103 \pm 0.8093$ and $32.533 \pm 2.1821$ for PCD compared to $11.103 \pm 0.7385$ and $31.950 \pm 2.1267$ for control group, respectively. History of PPH, retained placenta and other delivery complications is absent among $85 \%, 91.7 \%$ and $96.7 \%$ of the PCD group compared to $80 \%, 83.3 \%$ and $86.7 \%$ of the control group.

Table-3: Distribution of the study participants according to first and second stage of labour summary

\begin{tabular}{|c|c|c|c|c|}
\hline First and second stage of labour summary & $\begin{array}{l}\text { PCD }(\mathbf{N}=50) \\
\text { Mean } \pm \text { SD }\end{array}$ & $\begin{array}{l}\text { Control }(\mathrm{N}=50) \\
\text { Mean } \pm \mathrm{SD}\end{array}$ & Significance test & P value \\
\hline Duration of the $1^{\text {st }}$ stage (hours) & $8.9533 \pm 4.05915$ & $9.4683 \pm 4.41954$ & 0.665 & 0.507 \\
\hline Duration of $2^{\text {nd }}$ stage (minutes) & $54.5117 \pm 20.94502$ & $54.6217 \pm 17.35741$ & 0.31 & 0.975 \\
\hline Newborn weight (grams) & $4060.83 \pm 268.121$ & $3520.83 \pm 0.412$ & 1.009 & 0.315 \\
\hline \multicolumn{5}{|l|}{ Episiotomy or tear N (\%) } \\
\hline - Yes & $24(40)$ & $32(53.3)$ & $X^{2}=0.134$ & 0.200 \\
\hline$-\quad$ No & $36(60)$ & $28(46.7)$ & & \\
\hline
\end{tabular}

Table-3 shows no statistically significant differences between PCD and control group regarding the first and second stage of labour summary. Where, the mean duration of the $1^{\text {st }}$ and $2^{\text {nd }}$ stage of labour is $8.9533 \pm 4.05915$ and $54.5117 \pm 20.94502$ for PCD group compared to, 9.4683 \pm 4.41954 and $54.6217 \pm 17.35741$ for the control group, respectively. In addition, $60 \%$ of the PCD group not performed episiotomy compared to, $46.7 \%$ among control group. 
Wafaa Taha Ibrahim Elgzar et al; South Asian Res J Nurs Health Care; Vol-2, Iss- 1 (Jan-Feb, 2020): 1-11

Table-4: Distribution of the study participants according to third stage assessment progress

\begin{tabular}{|c|c|c|c|c|c|c|}
\hline Third stage of labour progress & \multicolumn{2}{|c|}{$\begin{array}{l}\text { PCD } \\
\text { Mean } \pm \text { SD }\end{array}$} & \multicolumn{2}{|c|}{$\begin{array}{l}\text { Control } \\
\text { Mean } \pm \text { SD }\end{array}$} & Significance test & P value \\
\hline \multicolumn{7}{|l|}{ Vital signs } \\
\hline Systolic BP & \multicolumn{2}{|c|}{$120.00 \pm 8.636$} & \multicolumn{2}{|c|}{$121.00 \pm 8.916$} & $t=0.624$ & 0.534 \\
\hline - Diastolic BP & \multicolumn{2}{|c|}{$78.00 \pm 6.120$} & \multicolumn{2}{|c|}{$77.75 \pm 5.706$} & $\mathrm{t}=0.231$ & 0.817 \\
\hline - Pulse & \multicolumn{2}{|c|}{$75.88 \pm 7.762$} & \multicolumn{2}{|c|}{$74.74 \pm 8.752$} & $\mathrm{t}=2.814$ & 0.092 \\
\hline Respiration & \multicolumn{2}{|c|}{$13.70 \pm 0.73$} & \multicolumn{2}{|c|}{$13.48 \pm 0.792$} & $\mathrm{t}=1.545$ & 0.125 \\
\hline $\begin{array}{l}\text { Time elapsed until appearance of placenta } \\
\text { separation signs/Minutes }\end{array}$ & \multicolumn{2}{|c|}{$3.5583 \pm 0.83915$} & \multicolumn{2}{|c|}{$5.7067 \pm 0.89393$} & $\mathrm{t}=13.572$ & $0.000^{\mathrm{a}}$ \\
\hline $3^{\text {rd }}$ stage duration / Minutes & \multicolumn{2}{|c|}{$5.1417 \pm 1.03138$} & \multicolumn{2}{|c|}{$7.4583 \pm 1.19877$} & $\mathrm{t}=11.572$ & $0.000^{\mathrm{a}}$ \\
\hline Amount of blood loss $/ \mathrm{ml}$ & \multicolumn{2}{|c|}{$195.45 \pm 13.994$} & \multicolumn{2}{|c|}{$265.45 \pm 21.920$} & $\mathrm{t}=20.849$ & $0.000^{\mathrm{a}}$ \\
\hline Placenta weight/g & \multicolumn{2}{|c|}{$580.333 \pm 64.97631$} & \multicolumn{2}{|c|}{$630.9167 \pm 65.61632$} & $\mathrm{t}=4.243$ & $0.000^{\mathrm{a}}$ \\
\hline \multirow[t]{2}{*}{ Uterotonic drugs dose } & \multicolumn{2}{|c|}{$7.6167 \pm 3.05371$} & \multicolumn{2}{|c|}{$7.0333 \pm 3.26754$} & $\mathrm{t}=0.722$ & 0.472 \\
\hline & $\mathbf{N}(60)$ & $\%$ & $\mathbf{N}(60)$ & $\%$ & & \\
\hline \multicolumn{7}{|l|}{ Uterotonic drug type } \\
\hline - Syntocinon & 51 & 85 & 55 & 91.7 & & \\
\hline - $\quad$ Syntocinon + methargin & 9 & 15 & 5 & 8.3 & $\mathrm{FET}=1.573$ & 0.716 \\
\hline \multicolumn{7}{|l|}{ Uterus condition after placenta delivery } \\
\hline - Contracted & 58 & 96.7 & 55 & 91.7 & $\mathrm{FET}=1.672$ & $\mathrm{P}=0.437$ \\
\hline - Relaxed & 2 & 3.3 & 5 & 8.3 & & \\
\hline \multicolumn{7}{|l|}{ Route of uterotonic drugs } \\
\hline $\mathrm{IM}$ & 2 & 3.3 & 5 & 8.3 & $\mathrm{FET}=1.408$ & $\mathrm{P}=0.235$ \\
\hline IV & 58 & 96.7 & 55 & 91.7 & & \\
\hline \multicolumn{7}{|l|}{ Retained placenta } \\
\hline No & 60 & 100 & 57 & 95 & $\mathrm{FET}=4.662$ & $\mathrm{P}=0.001^{\mathrm{a}}$ \\
\hline Yes & 0 & 0.0 & 3 & 5 & & \\
\hline
\end{tabular}

$\mathrm{t}=$ independent samples $\mathrm{t}$ test; $\mathrm{F}=$ Fisher exact test; a significant at 0.05

Table-4 shows no statistical significant differences between PCD and control group regarding vital signs during the $3^{\text {rd }}$ stage of labour, uterus condition after placenta delivery, type, dose and route of uterotonic drugs given during $3^{\text {rd }}$ stage. On the contrary, a statistical significant reduction in time elapsed until appearance of placenta separation signs, $3^{\text {rd }}$ stage duration, amount of blood loss during $3^{\text {rd }}$ stage, placenta weight and incidence of retained placenta in the PCD than the control group.

Table-5: Distribution of the study participants according to first 24 hours assessment parameters

\begin{tabular}{|c|c|c|c|c|c|c|}
\hline \multirow[t]{2}{*}{ First 24 hours assessment parameters } & \multicolumn{2}{|l|}{ PCD } & \multicolumn{2}{|c|}{ Control } & \multirow{2}{*}{$\begin{array}{l}\text { Significance } \\
\text { test }\end{array}$} & \multirow[t]{2}{*}{ P value } \\
\hline & $\mathbf{N}=\mathbf{5 0}$ & $\%$ & $\mathbf{N}=\mathbf{5 0}$ & $\%$ & & \\
\hline \multicolumn{7}{|l|}{ Uterus condition } \\
\hline - Contracted & 57 & 95.0 & 49 & 81.7 & \multirow[t]{2}{*}{$\mathrm{X} 2=11.88$} & \multirow[t]{2}{*}{$\mathrm{P}=0.001^{\mathrm{a}}$} \\
\hline - Relaxed & 3 & 5.0 & 11 & 18.3 & & \\
\hline \multicolumn{7}{|l|}{ Incidence of PPH } \\
\hline$-\quad$ No & 58 & 96.7 & 50 & 83.3 & \multirow[t]{2}{*}{$\mathrm{FET}=10.623$} & \multirow[t]{2}{*}{$\mathrm{P}=0.002^{\mathrm{a}}$} \\
\hline - Yes & 2 & 3.3 & 10 & 16.7 & & \\
\hline \multicolumn{5}{|l|}{ Need for blood transfusion } & \multirow{3}{*}{$\mathrm{FET}=13.623$} & \multirow[t]{3}{*}{$\mathrm{P}=0.001^{\mathrm{a}}$} \\
\hline$-\quad$ No & 58 & 96.7 & 50 & 83.3 & & \\
\hline - Yes & 2 & 3.3 & 10 & 16.7 & & \\
\hline \multicolumn{7}{|l|}{ Need for extra routine uterotonic drugs } \\
\hline$-\quad$ No & 57 & 95.0 & 49 & 81.7 & \multirow[t]{2}{*}{$\mathrm{X} 2=12.88$} & \multirow[t]{2}{*}{$\mathrm{P}=0.001^{\mathrm{a}}$} \\
\hline$-\quad$ Yes & 3 & 5.0 & 11 & 18.3 & & \\
\hline \multicolumn{7}{|l|}{ Type of routine uterotonic drugs used } \\
\hline - Syntocinon & 49 & 81.7 & 52 & 86.7 & \multirow[t]{2}{*}{$\mathrm{FET}=9.78$} & \multirow[t]{2}{*}{$\mathrm{P}=0.002^{\mathrm{a}}$} \\
\hline - Syntocinon + methargin & 11 & 18.3 & 8 & 13.3 & & \\
\hline \multicolumn{7}{|l|}{ Route of uterotonic drugs used } \\
\hline$-\quad$ IM & 11 & 18.3 & 13 & 21.7 & \multirow[t]{2}{*}{$\mathrm{FET}=11.788$} & \multirow[t]{2}{*}{$\mathrm{P}=0.004^{\mathrm{a}}$} \\
\hline \multirow[t]{2}{*}{ - } & 49 & 81.7 & 47 & 78.3 & & \\
\hline & \multicolumn{2}{|c|}{ Mean \pm SD } & \multicolumn{2}{|c|}{ Mean \pm SD } & & \multirow[b]{2}{*}{$\mathrm{P}=0.118$} \\
\hline \multirow[t]{2}{*}{$\begin{array}{l}\text { Dose of uterotonic drugs } \\
\text { Vital signs }\end{array}$} & \multicolumn{2}{|c|}{$5.0566 \pm 1.41985$} & \multicolumn{2}{|c|}{$8.6780 \pm 2.62902$} & $\mathrm{t}=1.577$ & \\
\hline & \multirow{2}{*}{\multicolumn{2}{|c|}{$104.3333 \pm 7.55913$}} & 10025 & -601504 & $t=11667$ & $\mathrm{P}=$ \\
\hline Systolle DF & & & & & & $0.000^{\mathrm{a}}$ \\
\hline - $\quad$ Diastolic BP & $64.916^{\circ}$ & .36586 & 60.300 & .97213 & $\mathrm{t}=10.745$ & $\begin{array}{l}\mathrm{P}= \\
0.001^{\mathrm{a}}\end{array}$ \\
\hline - Pulse & 83.466 & .78292 & 88.2 .76 & \pm 3.11022 & $\mathrm{t}=13.879$ & $\begin{array}{l}\mathrm{P}= \\
0.000^{\mathrm{a}}\end{array}$ \\
\hline - $\quad$ Temperature & $36.20 \pm$ & & $36.5 \pm 1$ & & $\mathrm{t}=1.002$ & $\mathrm{P}=0.103$ \\
\hline _ Respiration & 14.400 & .99490 & 14.283 & 097584 & $t=0.648$ & $\mathrm{P}=0.518$ \\
\hline Maternal hemoglobin(mg/dl) & 9.5234 & 6087 & $8.458 \pm$ & & $t=11.679$ & $\mathrm{P}=0.000^{\mathrm{a}}$ \\
\hline
\end{tabular}

(c) South Asian Research Publication, Bangladesh

Journal Homepage: www.sarpublication.com/sarjhss 


$$
\mathrm{t}=\text { independent samples } \mathrm{t} \text { test } \mathrm{X}^{2}=\text { chi-square } \quad \mathrm{F}=\text { Fisher exact test a significant at } 0.05 \text {. }
$$

Table-5 shows statistically significant differences between PCD and control group in all parameters assessed after 24 hours postpartum except for temperature and respiration. Where, $18.3 \%$ of the control group have relaxed uterus, and needs extra dose of uterotonic drugs compared to only $5 \%$ of the PCD group. Furthermore, only, 3.3\% complained from PPH and need blood transfusion among PCD group compared to, $16.7 \%$ of the control group. Syntocinon was the most common uterotonic drug used and mostly injected in intravenous solution in $81.7 \%$ in PCD group compared to, $86.7 \%$ among control group, respectively. The PCD group have lower systolic and diastolic BP with mean

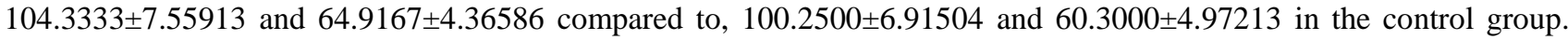

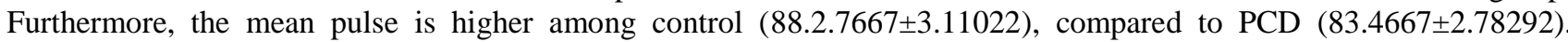

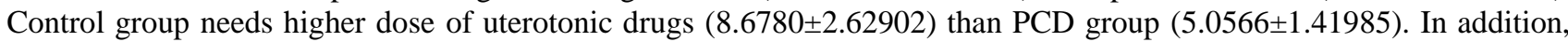
maternal hemoglobin is slightly higher in PCD group (9.5234 \pm 0.6087$)$ compared to, control (8.458 \pm 0.873$)$.

\section{DISCUSSION}

In the third stage current practices, early clamping of the umbilical cord from both sides and placenta delivery after appearance of placenta separation signs is common practice (brandet Andrews maneuver). Recently, WHO recommended PCD. This include unclamping the umbilical cord from the maternal side to drain the blood. Physiologically, it is supposed to decrease bulkiness of the placenta and allow the uterus to contract in more effective way. Consequently, decrease the $3^{\text {rd }}$ stage duration and decrease incidence and severity of PPH [17, 18].

The current study results revealed that there is a significant difference between PCD and control groups in relation to the $3^{\text {rd }}$ stage duration. This finding is consistent with the results of at least five recent studies. First, Afzal et al., [22] who investigated the impact of PCD on the third stage progress after normal vaginal delivery. They concluded that PCD significantly reduced $3^{\text {rd }}$ stage duration after spontaneous vaginal delivery. Second, Mithala et al., [23] who had conducted a randomized controlled trial in Buddhachinaraj Phitsanulok Hospital. They compared the amount of blood loss and the duration elapsed between fetus delivery and placenta delivery in PCD with early cord clamping group. They found that median duration of the $3^{\text {rd }}$ stage in the PCD group was significantly shorter than the control group. They concluded that PCD could reduce $3^{\text {rd }}$ stage duration and consequently reduced the amount of blood loss. Third, Mohamed et al., [24] who had conducted randomized controlled trial on180 women who underwent normal vaginal delivery. They compared the PCD with no PCD on the $3^{\text {rd }}$ stage progress. They stated that the $3^{\text {rd }}$ stage duration was significantly lower in PCD than no PCD group. Fourth, Kaba et al., [25] who studied the combination of PCD with 20 IU oxytocin on the $3^{\text {rd }}$ stage duration. They stated that the median $3^{\text {rd }}$ stage duration in the study group was 3.40 minutes compared to 5.10 minutes in the control group. This difference between the groups was statistically significant (p<0.01). Fifth, Al -Jeborry et al., 2010 [26] who had evaluated PCD after normal vaginal delivery as a part of the $3^{\text {rd }}$ stage management. They indicated that, PCD is simple, safe, and non-invasive method that can significantly reduce the $3^{\text {rd }}$ stage duration. Where, the mean duration of 3rd stage was $(5.35+2.3$ minutes $)$ in the PCD group compared to $(8.9+4.9$ minutes) in control group. Moreover, another eight randomized controlled clinical trials conducted in the duration ranged from 2005 to 2017 reported similar results with the current study [17, 20, 27-32].

The results of the present study are also supported by a recent meta-analysis including nine studies on 2653 patients. It is found that the $3^{\text {rd }}$ stage duration is significantly shortened (2,28 minutes) with PCD [33]. Furthermore, other three cochrane database of systemic reviews, which are, Hofmeyr 2015[15], Begley et al., 2011[34], Soltani 2005[18] studied the effect of PCD on the $3^{\text {rd }}$ stage. All of them have shown that PCD significantly reduced the $3^{\text {rd }}$ stage duration.

On the contrary, a recent study conducted by Vasconcelos et al., [35] has concluded that PCD had no effect in reducing the $3^{\text {rd }}$ stage duration. The $3^{\text {rd }}$ stage duration was approximately 14 minutes in both study and control group $(\mathrm{p}=0.66)$. In addition, Amorim 2015 [36] and Lankeshwara, 2008 [37] concluded that PCD had no effect on reducing the $3^{\text {rd }}$ stage duration. They reported opposite results by pointing out that PCD as a part of the $3^{\text {rd }}$ stage management increased the $3^{\text {rd }}$ stage duration. The differences between the current study and the latter group studies may be due to different intervention used in combination with PCD. For example if expectant placenta delivery is applied, the third stage duration will be longer than if active delivery of placenta is applied. In the current study, controlled cord traction in combination with oxytocin injection is applied after appearance of placenta separation signs. In addition, detailed information and data about 460 women in Amorim's trial [36] and Lankeshwara [37] are lacking, and this lack of information might be a source of deviation. One very old study done by Thomas et al, [21] has reported that no benefit of PCD on reducing the $3^{\text {rd }}$ stage duration.

The current study results pointed out that both blood loss and PPH incidence were lower among PCD group than control. This means that PCD may decrease amount of blood loss during third stage of labour and consequently decreasing PPH risk. 
These findings are in the same line with the results of at least five previously mentioned recent studies. First, Afzal et al., 2019 [22] who concluded that the mean blood loss in PCD group was statistically lower compared to the other group ( $\mathrm{p}<0.001)$. Second, Meena et al., 2017 [27] they revealed that blood loss and postpartum hemorrhage during $3^{\text {rd }}$ stage were significantly reduced in the study group compared to control group. Third, Royet al., 2016[28] that included 200 women who are randomized between PCD versus active management or active management only groups. The results showed that blood loss during the $3^{\text {rd }}$ stage of labour and incidence of PPH were significantly lower in the PCD compared to the other two groups. Fourth, Al-Jeborry et al., 2010 [26] revealed that PCD is simple, safe, and noninvasive method in reducing blood-loss during $3^{\text {rd }}$ stage of labour, thereby, preventing PPH. Fifth, Shravage and Silpa, 2007 [32], who found that the mean blood loss in PCD group was statistically lower compared to the control group. Furthermore, PCD reduced PPH incidence to $3 \%$ compared to $10 \%$ in the control group.

The results of the present study are also supported by two randomized controlled trials. They are Asicioglu et al., 2015 [30] and Sreelatha et al., 2013 [31]. Both of them shown that the average amount of blood-loss and incidence of PPH were significantly lower in the PCD group ( $\mathrm{p}<0.05$ each). Furthermore, two Cochrane database of systemic reviews, which are Hofmeyr et al., 2015 [15] and Begley et al., 2011[34] studied the effect of PCD during the $3^{\text {rd }}$ stage of labor. Both of them shown that PCD resulted in statistically significant reduction of blood loss during the $3^{\text {rd }}$ stage of labor .In addition, Mithala et al., 2018 [23] and Mohamed et al., 2017 [24] reported that the median blood loss in study group was lower than the control group. They also added, PPH was non-significantly less frequent among study group than among control group.

Furthermore, a recent 2017 meta-analysis including nine studies performed on 2653 women found that PCD reduced PPH incidence to 3\%. This finding is surprising since the same meta-analysis reported no reduction in amount of blood loss. The included studies in this meta-analysis were very heterogeneous; caution is needed before drawing definitive conclusions. The meta-analysis suggests that PCD is a simple and noninvasive procedure that seems to add to labour management, but more studies are still necessary to clarify its importance [33].

On the contrary, a recent study conducted by Vasconcelos et al., 2018 [35] has concluded that PCD had no effect in reducing blood loss or frequency of PPH during the $3^{\text {rd }}$ stage of labor. One explanation for the contradictory finding might be that the present study sample consisted of pregnant women at little risk of developing hemorrhage. Furthermore, all participants received prophylactic oxytocin for preventing postpartum hemorrhage. In addition, Amorim 2015 [36] concluded that PCD had no effect on reducing blood loss during the $3^{\text {rd }}$ stage of labour. Lankeshwara 2008 [37] also reported opposite results by pointing out that PCD as a part of the $3^{\text {rd }}$ stage management increased blood loss and PPH incidence.

The present study results showed that $3^{\text {rd }}$ stage duration was $5.1417 \pm 1.03138$ in PCD group compared to $7.4583 \pm 1.19877$ in the control group with a statistically significant difference between the two groups. The previously discussed, Wu H et al., 2017 [33] meta-analysis reported similar results to the current study as regard the duration of the $3^{\text {rd }}$ stage. The third stage duration among their participants was 2.28 minutes shorter than the control group. In addition, the previously discussed Mohamed A 2017[24] is online with the present study finding. They reported that the $3^{\text {rd }}$ stage duration was 4.4 minute in PCD group compared to 7.7 minute in the control group.

On the contrary, Taebi et al., 2012 [38] results, they reported that $3^{\text {rd }}$ stage was longer among PCD group than control. This discrepancy between the present study findings and the findings of Taebi et al., 2012 [38] might be attributed to the gestational age of study participants. Where, in the current study, mean gestational age was $39.187 \pm 0.8123$ while in the contradictory study was lower than 37 weeks. Based on previous literatures, $3^{\text {rd }}$ stage duration is longer among preterm deliveries. As with placenta aging at the end of pregnancy, it will be ready to separate. Combs and Laros [39] study drown some evidence of placenta aging hypothesis. They concluded that $3^{\text {rd }}$ stage duration at labour occurred on 32 to 35 weeks is significantly longer than that occurred at 36 weeks or more with p value less than 0.05 .

The present study revealed that postpartum hemoglobin is significantly higher in PCD group compared to control group. This result is in line with the previously mentioned studies conducted by Meena et al., 2017 [27] Mohamed et al., 2017 [24] Roy et al., 2016 [28] Mohammed \& Jeborry 2010 [40], and Giacalone 2000 [16]. All of them showed PCD significantly saves hemoglobin. They reported significance difference in postpartum hemoglobin level in PCD group than control group. In contrast, in a study done by Soltani et al., [18] there was no significant change in mean postpartum hemoglobin. Although Soltani et al., [18] reported no significance difference between PCD and control group regarding hemoglobin level, it is not lower than control group.

The present study revealed that there were significant difference between both groups regarding postpartum systolic BP, diastolic BP and pulse. This result is congruent with the previously mentioned study conducted by Mohamed 
et al., [24]. They concluded that the postpartum systolic blood pressure, diastolic blood pressure and pulse were affected among PCD group compared to control. No other trials had been found in this respect.

The current study results revealed that there were significant differences were observed between the PCD and control group in relation to the manual removal of placenta, need for blood transfusion, and uterine condition during postpartum period. These findings are partially in the same line with the previously mentioned studies conducted by Mithala et al., [23] and Mohamed et al., [24] they reported that the retained placenta was less frequent among PCD group than control. They further added that the need for postpartum blood transfusion was lower in PCD group compared to control without significant differences. Furthermore, Jongkolsiri \& Manotaya 2009 [17] concluded that no need for manual placental removal in PCD group. On the contrary, Soltani et al., [19] reported no difference in the need for a blood transfusion during postpartum period between PCD and control group. Furthermore, Sharma et al., [20] reported that the need for blood transfusion was not statistically significant differ among PCD group compared to control group and there was no case of retained placenta in either groups. Overall, the presented data showed that PCD could significantly shorten the $3^{\text {rd }}$ stage and the amount of blood loss. The method is easy to perform, safe, and does not increase in cadence of postpartum hemorrhage.

\section{CONCLUSION}

The present study results shows no statistical significant differences between PCD and control group regarding vital signs during the $3^{\text {rd }}$ stage, uterus condition after placenta delivery, type, dose and route of uterotonic drugs given during $3^{\text {rd }}$ stage. On the contrary, a statistical significant reduction in time elapsed until appearance of placenta separation signs, $3^{\text {rd }}$ stage duration, amount of blood loss during $3^{\text {rd }}$ stage, placenta weight and incidence of retained placenta in the PCD than control group. In the early postpartum assessment, the mean pulse is higher among control compared to PCD group. Control group needs higher dose of uterotonic drugs than PCD group. In addition, maternal hemoglobin is slightly higher in PCD group compared to control group.

\section{RECOMMENDATION}

PCD is safe, effective noninvasive intervention that may help in improving $3^{\text {rd }}$ stage progress and reduce $\mathrm{PPH}$ incidence. PCD should be added to third stage of labour intervention protocol. Future researches should be done to investigate benefits of PCD versus its harm.

\section{REFERENCES}

1. Alkema, L., Chou, D., Hogan, D., Zhang, S., Moller, A. B., Gemmill, A., Fat, D. M., Boerma, T., Temmerman, M., Mathers, C., \& Say, L. (2016). Global, regional, national levels and trends in maternal mortality between 1990 and 2015, with scenario-based projections to 2030: United Nations Maternal Mortality Estimation Inter-Agency Group. Lancet, 30:387.

2. Hogan, M., Foreman, K., \& Naghavi, M. (2010). Maternal mortality for 181 countries, 1980-2008: a systematic analysis of progress towards Millennium Development Goal 5. Lancet, 375:1609-1623.

3. Ministry of Health and Population Egypt, El-Zanaty and Associates and ICF International, Egypt Demographic and Health Survey 2014, Cairo, Egypt and Rockville, Maryland, USA: Ministry of Health and Population and ICF International, 2015.

4. Alkema, L., Chou, D., Hogan, D., Zhang, S., Moller, A. B., Gemmill, A., Fat, D. M., Boerma, T., Temmerman, M., Mathers, C., \& Say, L. (2014). Global Causes of Maternal Death: A WHO Systematic Analysis. Lancet Global Health. 2(6):323-e333.

5. Balchandani, U., \& Rai, D. (2007). A study of awareness regarding maternal mortality rate. Indian Journal Preventive and Social Medicine, 38(4), 193-196.

6. Alkış, İ., Karaman, E., Han, A., Ark, H. C., \& Büyükkaya, B. (2015). The fertility sparing management of postpartum hemorrhage: a series of 47 cases of Bakri balloon tamponade. Taiwanese Journal of Obstetrics and Gynecology, 54(3), 232-235.

7. Dahlke, J. D., Mendez-Figueroa, H., Maggio, L., Hauspurg, A. K., Sperling, J. D., Chauhan, S. P., \& Rouse, D. J. (2015). Prevention and management of postpartum hemorrhage: a comparison of 4 national guidelines. American journal of obstetrics and gynecology, 213(1), 76-e1-10.

8. Du, Y., Ye, M., \& Zheng, F. (2014). Active management of the third stage of labor with and without controlled cord traction: a systematic review and meta-analysis of randomized controlled trials. Acta Obstet Gynecol Scand, 93(7):626- 633.

9. Leduc, D., Senikas, V., Lalonde, A. B., Ballerman, C., Biringer, A., Delaney, M., ... \& Shepherd, D. (2010). Active management of the third stage of labour: Prevention and treatment of postpartum hemorrhage: No. 235 October 2009 (replaces No. 88, April 2000). 
10. Kaba, M., Engin Ustun, Y., Yapar Eyi, E. G., Timur, H., Unlu, B. S., Oksuzoğlu, A., Sosa, C. G., Althabe, F., Belizan, J. M., \& Buekens, P. (2011). Use of oxytocin during early stages of labor and its effect on active management of third stage of labor. Am Journal Obstet Gynecol, 204(3):238.e1-5.

11. Westhoff, G., Cotter, A. M., Tolosa, J. E. (2013). Prophylactic oxytocin for the third stage of labour to prevent postpartum haemorrhage. Cochrane Database Syst Rev, 10, 10:CD001808.

12. Weeks, A. D. (2008). The retained placenta. Best Pract Res Clin Obstet Gynaecol, 22(6):1103-11017.

13. Nankali, A., Keshavarzi, F., Fakheri, T., Zare, S., Rezaei, M., \& Daeichin, S. (2013). Effect of intraumbilical vein oxytocin injection on third stage of labor. Taiwan Journal Obstet Gynecol, 52(1):57-60.

14. Simposon, K., \& Creehan, P. (2014) Perinatal Nursing. 4th ed. Philadelphia: Lippincott Williams \& Wilkins, 34398.

15. Hofmeyr, G. J., Mshweshwe, N. T., \& Gülmezoglu, A. M. (2015). Controlled cord traction for the third stage of labour. Cochrane pregnancy and Childbirth Group. Cochrane Database Syst Rev.1:CD008020.

16. Giacalone, P. L., Vignal, J., Daures, J. P., Boulot, P., Hedon, B., \& Laffargue, F. (2000). A randomised evaluation of two techniques of management of the third stage of labour in women at low risk of postpartum haemorrhage. BJOG, 107(3):396-400.

17. Jongkolsiri, P., \& Manotaya S. (2009). Placental cord drainage and the effect on the duration of third stage of labour: randomized controlled trial. Journal Med Assoc Thai, 92(4):457-460.

18. Soltani, H., Dickinson, F., \& Symonds, I. M. (2005). Placental cord drainage after spontaneous vaginal delivery as part of the management of the third stage of labour. Cochrane Database of Systematic Reviews, (4).

19. Soltani, H., Poulose, T. A., \& Hutchon, D. R. (2011). Placental cord drainage after vaginal delivery as part of the management of the third stage of labour. Cochrane Database Syst Rev:CD004665.

20. Sharma, J. B., Pundir, P., Malhotra, M., \& Arora, R. (2005). Evaluation of placental drainage as a method of placental delivery in vaginal deliveries. Arch Gynecol Obstet, 271:343-345.

21. Thomas, I. L., Jeffers, T. M., Brazier, J. M., Burt C. L., \& Barr K. E. (1990). Does cord drainage of placental blood facilitate delivery of the placenta? Aust N Z Journal Obstet Gynaecol, 30(4):314-318.

22. Afzal, M. B., Bushra, N., Waheed, K., Sarwar, A., \& Awan, N. U. (2019). Role of placental blood drainage as a part of active management of third stage of labour after spontaneous vaginal delivery. Journal Pakistan Medical Assoc, 69(12):1790-1793.

23. Mithala, S., Sukonpan, K., \& Chunlaphakhee, C. (2018). The Comparison of Blood Loss after Vaginal Delivery between Placental Cord Drainage and Cord Clamping Before Placental Delivery in Buddhachinaraj Phitsanulok Hospital. Thai Journal of Obstetrics and Gynaecology, 26(1):34-41.

24. Mohamed, A., Bayoumy, H. A., Abou-Gamrah, A. A., \& El-shahawy, A. A. (2017). Placental Cord Drainage versus no Placental Drainage in the Management of Third Stage of Labour: Randomized controlled trial. The Egyptian Journal of Hospital Medicine, 68(1):1042-1048.

25. Kaba, M., Engin Üstün, Y., Yapar Eyi, E. G., Timur, H., Ünlü ,B. S., \& Öksüzoğlu, A. (2017). Placental Blood Drainage Shortens Duration of the Third Stage of Labor in Women Slowly Administered 20 IU Oxytocin. Gynecol Obstet Reprod Med, 23(1):6-10

26. Al-Jeborry, M. M., Gatea, A. K., \& Witwit, S. J. (2010). Placental cord drainage after vaginal delivery as a part of management of third stage of labour. Medical journal of babylon, 7(3-4):404-409

27. Meena, S. A., Bebincy, D. S., \& Devika. (2017). Placental cord blood drainage after vaginal delivery as part of the management of third stage of labour: a systematic review of randomized controlled clinical trial. International Journal of Reproduction, Contraception, Obstetrics and Gynecology, 6:4001-4005.

28. Roy, P., Sujatha, M. S., Bhandiwad, A., Biswas, B., \& Chatterjee, A. (2016). Placental Blood Drainage as a Part of Active Management of Third Stage of Labour after Spontaneous Vaginal Delivery. Journal of Obstetrics and Gynecology of India, 66(1):242-245.

29. Choppala, N., \& Ramana Bai, P. V. (2016). A study to evaluate the effectiveness of simple technique of placental drainage in control of third stage blood loss. MRIMS Journal Health Sciences, 4:2-5.

30. Asicioglu, O., Unal, C., Asicioglu, B. B., Temizkan, O., Yildirõm, G., Arici, B., \& Gulova, S. (2015). Influence of placental cord drainage in management of the third stage of labor: a multicenter randomized controlled study. American Journal Perinatol, 32(4):343-350.

31. Sreelatha, S., Vedavathy, N., \& Kazi, A. (2013). Effect of placental cord blood drainage on the third stage of labor. Journal Evolution Medical Dental Sciences, 2(21):3770-3773.

32. Shravage, J. C., \& Silpa, P. (2007). Randomized controlled trial of placental blood drainage for the prevention of postpartum hemorrhage. Journal Obstet Gynecol India, 57(3):213-215.

33. Wu, H. L., Chen, X. W., Wang, P., \& Wang, Q. M. (2017). Effects of placental cord drainage in the third stage of labour: A metaanalysis. Scientific Repo Rts, 7(1):1-8.

34. Begley, C. M., Gyte, G. M., Devane, D., McGuire, W., \& Weeks, A. (2011). Active versus expectant management for women in the third stage of labour. Cochrane Database Syst Rev, CD007412.

35. Vasconcelos, F. B., Katz, L., Coutinho, I., Lins, V. L., \& de Amorim, M. M. (2018). Placental cord drainage in the third stage of labor: Randomized clinical trial. Plos One, 13(5):1-10 
36. Amorim, M. (2105). Placental cord drainage in the third stage of labor. International Journal Obstetrics and Gynecology, 131:E226.

37. Lankeshwara, D. (2008). Placental cord drainage after vaginal delivery in the management of the third stage of labour. Post Graduate of Medicine (PGIM), University of Colombo, Sri Lanka. Thesis for MD (Obsterics and Gynecology) Part 11.

38. Taebi, M., Abedzadeh Kalahroudi, M., Sadat, Z., \& Saberi, F. (2012). The duration of the third stage of labor and related factors. Iranian Journal of Nursing and Midwifery Research, 17(2).

39. Combs, C. A., \& Laros Jr, R. K., (1991). Prolonged third stage of labor: Morbidity and risk factors. Obstetrics \&amp Gynecology, 77(6), 863-867.

40. Mohammed, M., \& Jeborry A. I. (2010). Efficacy of cord blood drainage, at college of Medicine. Department of Obstetrics Gynecology, Babylon University. Medical Journal Babylon. 